\title{
Effect of Fungicide Mobility and Application Timing on the Management of Grape Powdery Mildew
}

\author{
Brent Warneke, ${ }^{1}$ Lindsey D. Thiessen, ${ }^{2}$ and Walter F. Mahaffee ${ }^{3, \dagger}$ \\ ${ }^{1}$ Department of Botany and Plant Pathology, Oregon State University, Corvallis, OR 97331 \\ ${ }^{2}$ Department of Entomology and Plant Pathology, North Carolina State University, Raleigh, NC 27695 \\ ${ }^{3}$ Horticultural Crops Research Laboratory, U.S. Department of Agriculture-Agricultural Research Service, Corvallis, OR 97331
}

\begin{abstract}
Grape powdery mildew (GPM) fungicide programs consist of 5 to 15 applications, depending on region or market, in an attempt to achieve the high fruit quality standards demanded by the market. Understanding how fungicides redistribute and targeting redistributing fungicide to critical crop phenological stages could improve fungicide protection of grape clusters. This study evaluated fungicide redistribution in grapevines from major fungicide groups labeled for GPM control. Translaminar and xylem redistribution was examined by placing fungicideimpregnated filter disks on the adaxial or abaxial leaf surface of detached leaves for $10 \mathrm{~min}$ and then incubating for $48 \mathrm{~h}$ before inoculating the abaxial surface with conidia. Vapor redistribution used Teflon disks

flowering potted vines. All fungicides tested redistributed through at least one mechanism. Fungicide timing at critical phenological stages (early, mid, and late bloom) was assessed in small plots of cultivar Pinot noir vines. The application of trifloxystrobin, quinoxyfen, or fluopyram at different bloom stages showed that applications initiated at end of bloom resulted in the lowest berry infection probabilities of $0.073,0.097$, and 0.020 , respectively. The results of this study suggest that integrating two carefully timed applications of redistributing fungicides initiated at end of bloom into a fungicide program may be an effective strategy for wine grape growers in western Oregon to produce fruit with low GPM infection.
\end{abstract} sprayed with fungicides and placed on the abaxial leaf surface of detached leaves $48 \mathrm{~h}$ before inoculation. Disease development was rated 10 days later. Translaminar movement through calyptra was tested using
Keywords: disease management, Erysiphe necator, fungicide mobility, fungicide redistribution, grape, grape powdery mildew, Vitis vinifera
One of the most important diseases of wine grapes (Vitis vinifera) the world over is grape powdery mildew (GPM) caused by the obligate biotroph, Erysiphe necator (Gadoury et al. 2012). Even at low levels (1 to 5\%), E. necator infections on clusters can decrease wine quality (Stummer et al. 2003), and wine producers have been known to reject grape crops with $>3 \%$ infected berries (Bettiga et al. 2013; Hellman 2003). Because of a lack of constitutive resistance in traditional $V . v i$ nifera cultivars, management of GPM relies on regular fungicide applications that can amount to as much as $37 \%$ gross value of production (Sambucci et al. 2014). In the United States alone, 45 million pounds of fungicides are used on grapes per year at a cost of around \$123 million (Gianessi and Reigner 2005). Conventional GPM management programs begin soon after bud break (March to April) and continue until véraison (late July through August), with the goal of delaying the exponential phase of the epidemic for as long as possible (Lybbert et al. 2016; Madden et al. 2007; Sambucci et al. 2017). After initiation, applications typically continue on a 7 - to 21-day schedule depending on the labeled application interval of the products used (Sambucci et al. 2014). Little consideration is given as to how to take advantage of fungicide redistribution to improve disease management.

Grape tissues gain ontogenic resistance to E. necator infection as they age that is strongly expressed in berries (Gadoury et al. 2003). $V$. vinifera inflorescences and young berries are highly susceptible to

${ }^{\dagger}$ Corresponding author: W. F. Mahaffee; walt.mahaffee@ars.usda.gov

Funding: This work was supported by Oregon Wine Board grants 2015-1826, 2016-1826, and 2017-1826 and U.S. Department of Agriculture-Agricultural Research Service (USDA-ARS) CRIS grant 5358-22000-041-00D.

The author(s) declare no conflict of interest.

Accepted for publication 21 October 2019.

This article is in the public domain and not copyrightable. It may be freely reprinted with customary crediting of the source. The American Phytopathological Society, 2020 infection until berries are 3 to $4 \mathrm{~mm}$ in diameter (BBCH 75) (Lorenz et al. 1995); then, they become nearly immune to infection (Ficke et al. 2002; Gadoury et al. 2003). Thus, fungicide applications before $\mathrm{BBCH} 75$ are important to maintaining disease-free fruit. Gadoury et al. (2003) showed that two sequential applications of kresoximmethyl applied to individual grape inflorescences at bloom and 10 days later provided similar disease control as eight fungicide applications to individual shoots beginning at $15-\mathrm{cm}$ shoot growth. Similarly, in the management of hop powdery mildew on hop cones, fungicide programs that ceased after cones developed some level of ontogenic resistance had the same disease control as season-long programs (Gent et al. 2014; Nelson et al. 2015). Further improvement of GPM management may be obtained by optimizing fungicide selection during grape bloom.

Timing fungicide applications to specific phenological stages could provide a way to standardize GPM management programs over years and improve disease control. Kast and Bleyer (2011) showed that three consecutive sprays (one before flowering, one during flowering, and one when the berries were $2 \mathrm{~mm}$ in diameter; $\mathrm{BBCH} 55, \mathrm{BBCH} 65$, and $\mathrm{BBCH} 73$, respectively) had $90 \%$ of the effect at reducing GPM on clusters as a program containing seven sprays. Kast and Bleyer (2011) used a variety of fungicides but did not evaluate their individual efficacy at the phenological stages investigated. When myclobutanil was applied three times at 14-day intervals from immediate prebloom, nearly complete control of grape black rot (causal agent Guignardia bidwellii) was achieved on clusters. In addition, two applications initiated immediately prebloom provided similar control to three applications in 3 of 4 years (Hoffman et al. 2004). Furthermore, timing fungicide applications to phenological stages may take advantage of the unique chemical attributes of redistributing fungicides.

Redistribution of active ingredients around plant tissues is an important characteristic of many modern synthetic fungicides that aids in their efficacy and reliability (Klittich 2014). There are multiple mechanisms of redistribution (e.g., via xylem, translaminar, and vapor), with each mechanism advantageous in its own way for enhancing fungicidal coverage of plant tissues. The degree of redistribution and the resulting efficacy differences have not been well investigated for many fungicidal products. For example, when quinoxyfen was 
applied during early hop flowering, powdery mildew control was improved by 32 to $52 \%$ compared with treatment regimens that did not use quinoxyfen (Nelson et al. 2015). Quinoxyfen redistributes via xylem and vapors, and therefore, fungicide redistribution could explain some of the increased efficacy of applications during hop flowering (Henry 2003). Vine canopies are typically large and dense, with leaves often reducing deposition of fungicide to inflorescences (Austin et al. 2011); thus, redistribution of fungicide to inflorescences and clusters may be important.

We wanted to test the hypothesis that timing redistributing fungicides to particular phenological growth stages of $V$. vinifera will improve the management of GPM. The objectives of this study were to examine the redistribution properties of fungicides used to control grapevine powdery mildew and determine the application timing in relation to grape bloom that most effectively reduces the proportion of infected grape berries for five commonly used fungicides with varying redistribution profiles.

\section{Materials and Methods}

Detached leaf fungicide redistribution leaf collection. To determine the mechanism(s) and extent of redistribution of fungicidal products, detached leaf bioassays with $E$. necator growth on the adaxial leaf surface as a bioindicator (see below) were developed to examine xylem, translaminar, and vapor mechanisms (Table 1). Young succulent $V$. vinifera 'Pinot noir' leaves (fourth to sixth node from the growing tip) collected from a greenhouse kept free of powdery mildew with nightly sulfur vaporization were surface disinfested with $0.06 \%$ sodium hypochlorite and placed in double-decker petri dishes with tap water in the bottom dish (Quinn and Powell 1982). Inside the double-decker petri dishes, the RH was approximately $70 \%$ owing to leaf transpiration and evaporation of water from the bottom petri dish, but growth of $E$. necator was not inhibited (data not shown). Leaves for all assays were incubated in a growth chamber at $22^{\circ} \mathrm{C}$ with a 16 -h photoperiod and $\mathrm{RH}$ of $55 \pm 3 \%$ for the duration of the experiment.

Detached leaf fungicide application and inoculation. Sixmillimeter-diameter discs of sterilized Whatman \#54 filter paper and surface-sterilized 0.5-mm-thick virgin polytetrafluoroethylene (PTFE) were made using a flame-sterilized standard hole punch. Filter paper discs were used in the xylem and translaminar experiments, and PTFE discs were used in the vapor experiments.

For the xylem and translaminar assays, filter paper discs were submerged in commercial fungicide (Table 1) suspensions (made with nonsterile tap water) or nonsterile tap water and then shaken with an orbital shaker at $80 \mathrm{rpm}$ for $10 \mathrm{~min}$. Filter paper discs were placed centered on the intersection of the primary vein to the left and right of the midvein and the first branching secondary vein on the adaxial surface of the leaf for the xylem redistribution assay and the abaxial leaf surface for the translaminar assay. After resting on the leaf for $10 \mathrm{~min}$, discs were removed and discarded, and the leaves were incubated for $48 \mathrm{~h}$ prior to inoculation.
For the vapor assay, discs made of virgin PTFE (0.5-mm thickness) were used to prevent diffusion of fungicide to the leaf surface. PTFE discs were affixed to a small piece of wax paper with a portion of vacuum grease. Fungicide or nonsterile tap water was applied to PTFE discs by holding a Preval sprayer (Chicago Aerosol) $25 \mathrm{~cm}$ from the disc at an approximate angle of incidence of 30 to $45^{\circ}$ and applying an approximately 0.5 -s burst of spray; then, they were allowed to dry before placing (as described above) them, fungicide-coated surface up, on the adaxial surface of leaves for the entire duration of the assay. Leaves were incubated for $48 \mathrm{~h}$ prior to inoculation. In all experiments, each leaf had a fungicide treatment and a water control disc.

An E. necator population originally collected from Oregon vineyards was maintained on cultivar Chardonnay seedlings in a growth chamber and used as inoculum for all detached leaf experiments. Leaves were inoculated with E. necator conidia in a $55 \times 55 \times$ 100 -cm (length $\times$ width $\times$ height) settling tower. Three to five Chardonnay seedlings heavily infected with $E$. necator were suspended $25 \mathrm{~cm}$ below the top of the tower and sprayed with three approximately 0.5 -s bursts of compressed air. Spores were allowed to settle for 5 min after placing a lid on the tower. Leaves were incubated until relatively uniform $E$. necator growth was observed across the leaf surface (approximately 7 to 10 days), and then, they were assessed by measuring the area of disease inhibition (Fig. 1B).

Detached leaf disease assessment and analysis. The area of disease inhibition was measured using an optical micrometer calibrated to millimeters in a Leica MKZ stereomicroscope with epiluminescence at $27 \times$ magnification. For xylem and translaminar assays, three measurements starting at the center of each filter paper location were conducted as follows: one acropetally along the main vein that the fungicide-impregnated disc was applied to $(A)$, one basipetally along the same vein $(B)$, and one perpendicular to the vein extending through the vein intersection $(P)$ where the fungicide-impregnated disc was applied (Fig. 1). The criterion used to determine where to stop the measurements was where mycelia came within $1 \mathrm{~mm}$ of a graduation on the ruler in any direction. The area of E. necator growth inhibition was calculated (equation 1):

Area of inhibition $\left(\mathrm{mm}^{2}\right)=((0.5 \times P) \times A)+((0.5 \times P) \times B)$

For the vapor assay, after 7 to 10 days, inhibition of E. necator was exemplified as a torus around the PTFE disc that was not always symmetrical. To account for these irregularities, the maximum and minimum distances from the edge of the PTFE disc to E. necator mycelia were measured with an optical micrometer, averaged, and used to calculate an area (millimeters ${ }^{2}$ ) of inhibition that excluded that of the PTFE disc (equation 2):

Area of inhibition $\left(\mathrm{mm}^{2}\right)$

$=\pi(\text { average radius of inhibition }+ \text { disk radius })^{2}-$ disk area

Table 1. Fungicides and rates used in 2015 to 2017 experimental trials at the Botany and Plant Pathology Field Laboratory vineyard and in planta fungicide redistribution assays

\begin{tabular}{|c|c|c|c|c|c|}
\hline \multirow[b]{2}{*}{$\begin{array}{l}\text { Fungicide } \\
\text { trade name }\end{array}$} & \multirow[b]{2}{*}{$\begin{array}{c}\text { Fungicide } \\
\text { technical name }\end{array}$} & \multicolumn{3}{|c|}{ Fungicide mechanism } & \multirow[b]{2}{*}{$\begin{array}{l}\text { Application rate } \\
(\text { amount/ha) }\end{array}$} \\
\hline & & $\begin{array}{l}\text { FRAC } \\
\text { group }^{x}\end{array}$ & Mode of action & Redistribution properties & \\
\hline Quintec $^{\mathrm{z}}$ & Quinoxyfen & 13 & $\begin{array}{l}\text { Unknown; inhibition of cell signaling and } \\
\text { appressorium development proposed }\end{array}$ & Xylem, vapor & $292 \mathrm{ml}$ \\
\hline Toledo $^{\mathrm{z}}$ & Tebuconazole & 3 & Sterol demethylation inhibition & Translaminar, xylem & $0.28 \mathrm{~kg}$ \\
\hline Rhyme & Flutriafol & & & Translaminar, xylem, vapor & $292 \mathrm{ml}$ \\
\hline Luna Privilege $^{\mathrm{z}}$ & Fluopyram & 7 & Succinate dehydrogenase inhibition & Translaminar, xylem, vapor & $292 \mathrm{ml}$ \\
\hline Flint $^{\mathrm{Z}}$ & Trifloxystrobin & 11 & Quinone outside inhibitor of mitochondrial bc1 complex & Translaminar, vapor & $0.14 \mathrm{~kg}$ \\
\hline $\begin{array}{l}\text { Microthiol } \\
\text { Disperss }^{z}\end{array}$ & Sulfur & M2 & Unknown multisite activity & Vapor & $3.36 \mathrm{~kg}$ \\
\hline Vivando & Metrafenone & U8 & Unknown; disruption of actin assemblage proposed & Translaminar, vapor & $804 \mathrm{ml}$ \\
\hline
\end{tabular}

${ }^{\mathrm{w}}$ All fungicides listed were used in detached leaf mobility assays.

${ }^{x}$ Fungicide Resistance Action Committee (FRAC) group number assigned to each class of fungicide chemistry based on mode of action.

y Fungicides for all experiments were mixed at concentrations at the listed rate applied in a volume of 467 liters of water per hectare at full canopy (50 gallons/ acre).

${ }^{\mathrm{z}}$ Fungicides used in the small plot phenological and fungicide translocation through calyptra experiments. 
All assays were arranged in a completely randomized design with four replicate leaves per treatment and repeated at least once, with similar treatment effects each time. Mean areas of inhibition (millimeters ${ }^{2}$ ) were used as the response to fit generalized linear models with fungicide as the explanatory variable using the glmm function in R 3.3.2 (R Core Team 2016). Treatment comparisons were conducted using the emmeans function (estimated marginal means) from the emmeans package (Lenth 2018). $P$ values were adjusted with the Dunnett method to account for a group of seven tests.

Fungicide translocation through calyptras. To determine if fungicide could translocate through calyptras and inhibit growth of $E$. necator on berries after calyptras detach, a greenhouse experiment was designed using potted greenwood cuttings of $V$. vinifera 'Pixie' (Cousins 2012) grape plants in 2-liter pots that were maintained powdery mildew free in a greenhouse through nightly vaporization of sulfur. Inflorescences at BBCH 55 to 57 (flowers appressed - flowers separating) were marked, and one leaf above and one leaf below the inflorescence were removed to prevent fungicide deposition on them. The experiment was arranged in a randomized complete block design with the experimental unit as a single treated inflorescence on a potted plant. There were four replicate blocks in time containing five fungicides and a water control. Experiment was repeated with similar treatment effects.

Fungicides (Table 1) were suspended in unsterilized tap water in glass Preval spray jars (Chicago Aerosol). A 1-s spray burst (approximately $1 \mathrm{ml}$ ) was applied to each side of the inflorescence; then, plants were placed in a greenhouse without sulfur volatilization for 7 days to allow the calyptras to detach. Greenhouse day and night temperatures were $24 \pm 3$ and $16 \pm 3^{\circ} \mathrm{C}$, respectively. Greenhouse light setting was a light cycle of $16: 8 \mathrm{~h}$ (day:night); average $\mathrm{RH}$ was maintained at $58 \pm$ $13 \%$. After 7 days, most calyptras had detached, and inflorescences were inoculated with a conidial suspension of 20,000 conidia per milliliter in sterilized distilled water containing $0.05 \%$ TWEEN 20. A Nalgene hand pump sprayer was used to deliver a 1-s burst of spray (approximately $1 \mathrm{ml}$ ) to each side of the inflorescence. After inoculation, inflorescences were incubated in the same greenhouse for 7 to 10 days before microscopic examination. The numbers of infected and uninfected berries/flowers were recorded.

The proportion of infected berries was used as the response to fit a linear model with fungicide as the explanatory variable using the base $\mathrm{lm}$ function in R 3.3.2 (R Core Team 2016). Treatment comparisons were conducted using the Tukey honest significant difference $(P<0.05)$ from the agricolae package (Mendiburu 2016).

Research vineyard. A 19-year-old vineyard of Pinot noir (clone $2 \mathrm{~A}$ on $420 \mathrm{~A}$ root stock) located at the Oregon State University Botany and Plant Pathology Field Laboratory (Corvallis, Oregon) was used to conduct the small plot phenological application timing, field mobility assessment, and fungicide rotation experiments. Vines were arranged with $1.5 \times 1.8-\mathrm{m}$ spacing, trained in a bilateral Guyot system, and cane pruned with vertical shoot positioning. After bud break, shoots were thinned to one per node and hedged as needed when shoots grew above the top of the trellis (approximately $1.8 \mathrm{~m}$ ). The vineyard was scouted for GPM flag shoots after bud break, and any shoots found were removed. There was no fruiting zone leaf removal, irrigation, or fertilization over the course of the season as is common practice.

Small plot phenological experiment. Five fungicides were chosen because of their widespread use in the industry and varied redistribution profiles (Table 1). Three growth stages (inflorescence elongation, 50\% bloom, and end of bloom; $\mathrm{BBCH} 55, \mathrm{BBCH} 65$, and $\mathrm{BBCH} 69$, respectively) during grapevine flowering were chosen to time fungicide applications owing to the high susceptibility of inflorescences to infection and the influence of inflorescence architecture on fungal spore deposition (Gee et al. 2008; Shavrukov et al. 2004). The inflorescence stages and fungicides were used in a $3 \times 5$ factorial design and arranged in a randomized complete block design with four replications. The experimental unit consisted of a linear section of five grapevines referred to hereafter as a plot. There were 17 plots of grapevines in every block: the 15 treatments from the factorial and the 2 control treatments of water and wettable sulfur (WS; Microthiol Disperss; UPI) applied every 14 days. The experiment was conducted in the same vineyard in 2015 and 2016, with rerandomization of treatments within blocks in 2016.

All plots except the water control received WS applications every 14 days beginning when shoots were 20 - to $30-\mathrm{cm}$ (8- to 12 -inches) long (Fig. 2). WS applications were made at a concentration of 7.2 $\mathrm{g} /$ liter of formulated product (5.76 g/liter of active ingredient) the whole season and applied at a rate of 467 liter/ha at full canopy. An estimated 14 days prior to approximately $50 \%$ of the vineyard reaching each phenological stage, WS applications in phenological plots were ceased. When approximately $50 \%$ of the vineyard reached each phenological stage, fungicides (Table 1) were applied to plots specified to receive each fungicide at that phenological stage. For example, when the whole vineyard reached inflorescence elongation (BBCH 55), applications of each fungicide (Table 1) were made to
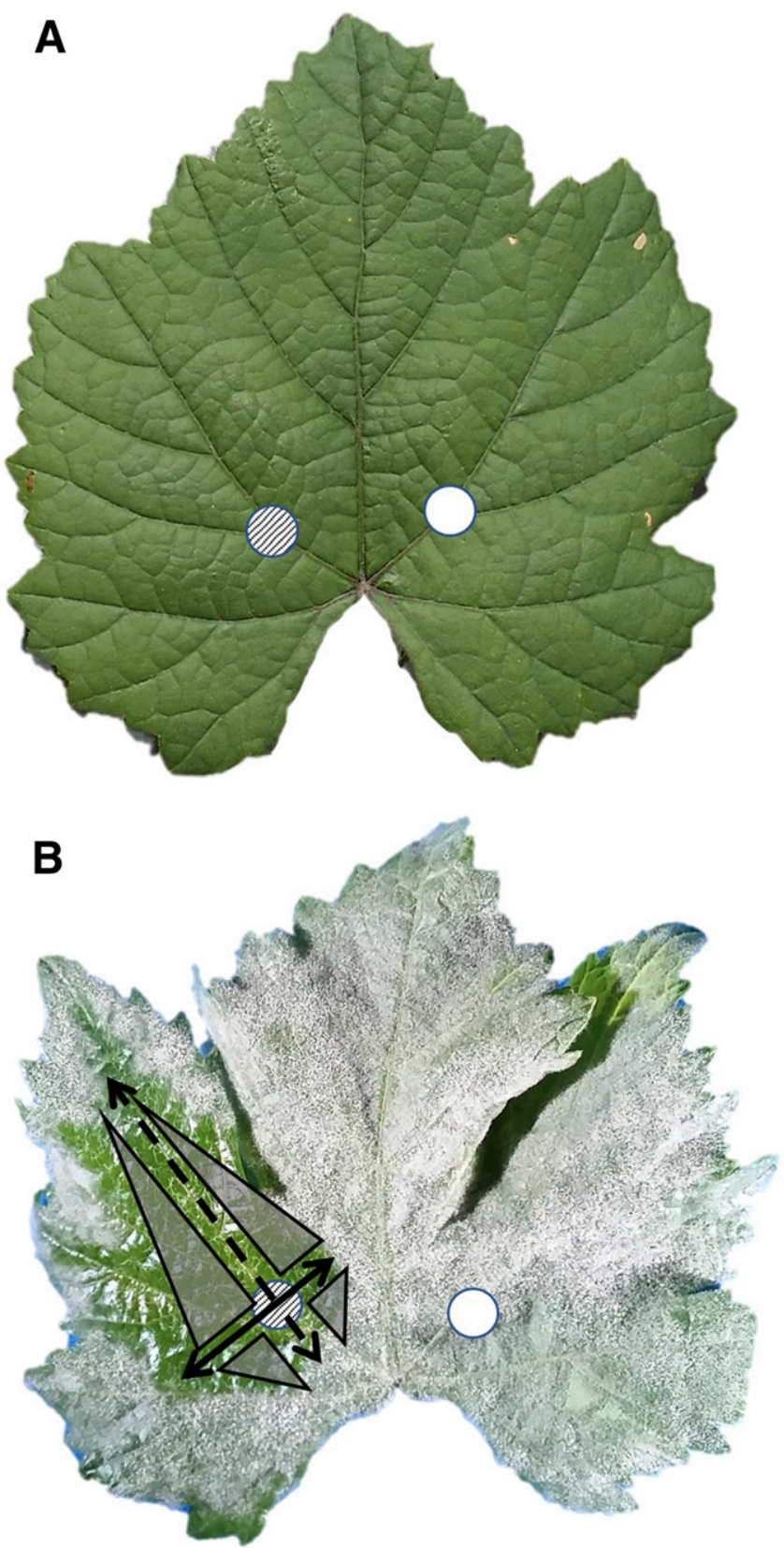

Fig. 1. Detached leaf fungicide redistribution assay setup and data collection illustration. Discs were placed at the first major vein intersection on the side lobes on leaves A, where a fungicide-treated disc is (represented by the dashed disc; the untreated water control disc is not dashed). B, Mildew-infected leaf with illustrative discs, mildew-free measured area with acropetal and basipetal measurements $(A+$ $B$; equation 1) indicated with a dashed line, and perpendicular measurement $(P$; equation 1) indicated with a solid line. Overlaid triangles indicate the approximate areas calculated. Not to scale. 
the specific $\mathrm{BBCH} 55$ plots for a total of five plots treated per replication. As the plants continued to develop, the $\mathrm{BBCH} 65$ and $\mathrm{BBCH}$ 69 plots received their applications. Throughout this period, the 14day-interval WS control treatment received applications regardless of plant development. A second application of the same fungicide was made to those same phenological plots 14 days after the initial phenologically timed treatment. Sulfur applications resumed 14 days after the second application to phenologically treated plots and then continued at a 14-day interval until veraison.

All WS and phenological fungicide treatments (Fig. 2) were applied using a custom ducted, over-the-row, air-blast sprayer with venturi nozzles (Rears Manufacturing). Nozzles were fitted with TeeJet CP4916-30 spray discs (Spraying Systems Co.) and operated at $207 \mathrm{kPa}$, with each nozzle yielding an output of $6.25 \times$ $10^{-6} \mathrm{~m}^{3} / \mathrm{s}$. Early-season applications started with 4 nozzles in use (two on each side of the sprayer) at an approximate output of 203 liters/ha, and 1 nozzle per side was added as the canopy grew until the maximum of 10 nozzles was reached. Every time that a nozzle was added to each side of the sprayer, total sprayer output increased by 102 liters/ha.

All data were collected from the middle three vines in each plot to minimize plot-plot interference. GPM incidence assessments on leaves were conducted weekly starting at approximately $30-\mathrm{cm}$ shoot growth and continued until véraison $(\mathrm{BBCH} 15$ and $\mathrm{BBCH} 83$, respectively). Leaf disease incidence was assessed visually by examining 10 arbitrarily selected leaves per plant between 4 and 7 leaves down from the topmost unfurled leaf on a shoot and recording the number out of 10 that was infected. To assess cluster infection levels, 10 clusters per plot were arbitrarily selected just prior to véraison, collected individually in a zip sandwich bag, and frozen at $-20^{\circ} \mathrm{C}$ until assessment. For cluster disease assessments, frozen berries were removed from the rachis of each cluster individually, and 25 berries per cluster were randomly selected for microscopic examination. Berry disease incidence was microscopically assessed to detect diffuse $E$. necator infections invisible to the naked eye (Gadoury et al. 2007). The presence of hyphae and/or two to three groupings of necrotized epidermal cells were used as the indicator of infection. The number of infected berries out of 25 on each cluster was recorded.

Leaf disease incidence data were used to calculate as absolute area under disease progress curves (AUDPCs) using the Agricolae package (Mendiburu 2016). Leaf AUDPCs were used to fit linear mixed effects models using the lme function from the nlme package, with block as a random effect (Mendiburu 2016; Pinheiro et al. 2016; R Core Team 2016; Warnes et al. 2015). Year was shown to have a significant effect on model fit (likelihood ratio $=17.2,1$ degree of freedom, $P<0.001$ ), and therefore, analysis of individual years was done to avoid homogenization of variance between years. Linear contrasts of means were used to compare AUDPCs with nontreated water and WS controls, with $P$ values adjusted using the Bonferroni correction to account for 16 comparisons. The number of infected berries per experimental unit ( $n=250)$ was used as a binomially distributed probability of berry infection and modeled using a generalized linear mixed model (GLMM). A simple effects model was used to compare disease levels among all treatments. Separate models were fit to each year of data to avoid homogenization of variance and observe trends between years, with block included as a random effect. Treatment contrasts were conducted with the emmeans package, and fits of all GLMMs were checked with the DHARMa package and an overdispersion function (Bolker et al. 2009; Hartig 2016; Lenth 2018). Uncertainty was estimated using asymptotic 95\% confidence intervals after comparison of profile, bootstrap, and asymptotic methods. Any overdispersion because of extrabinomial variation was corrected using an observationallevel random effect (Harrison 2014).

Field redistribution assessment. Fungicide redistribution to clusters from leaves was investigated concurrently in a field setting during the 2015 and 2016 phenological application timing experiments. A set of 10 clusters was marked in every growth stage $\times$ fungicide treatment plot and covered with plastic zip top sandwich bags (BiMart) during the phenologically timed fungicide applications to prevent any fungicide deposition directly onto the clusters. Plastic bags were removed from marked inflorescences immediately following fungicide applications. The experimental design and units were as described above. Clusters were harvested and assessed for disease as described above. Statistical analysis was conducted using GLMM methods as described above.

Fungicide rotation experiment. To investigate the efficacy of rotating quinoxyfen and fluopyram applications at BBCH 69 (end of bloom), a trial was conducted in the same research vineyard in 2017. Trifloxystrobin was excluded because of widespread FRAC 11 fungicide resistance in Oregon grape-growing regions (Warneke et al. 2016). The experiment was arranged as a randomized complete block with treatments applied to a 49-m row and four replications. Each 49-m row served as the experimental unit, except for the water-treated control, which consisted of five vines at alternating ends of each calendar sulfur row. The water-treated control was confined to a smaller area to prevent biases in disease levels among adjacent rows because of high levels of sporulation from those plots. Treatments consisted of water-treated control, WS control, and phenologically timed treatments, where early-season WS applications (described above) were followed by treatments consisting of single applications of fluopyram or quinoxyfen and rotations between

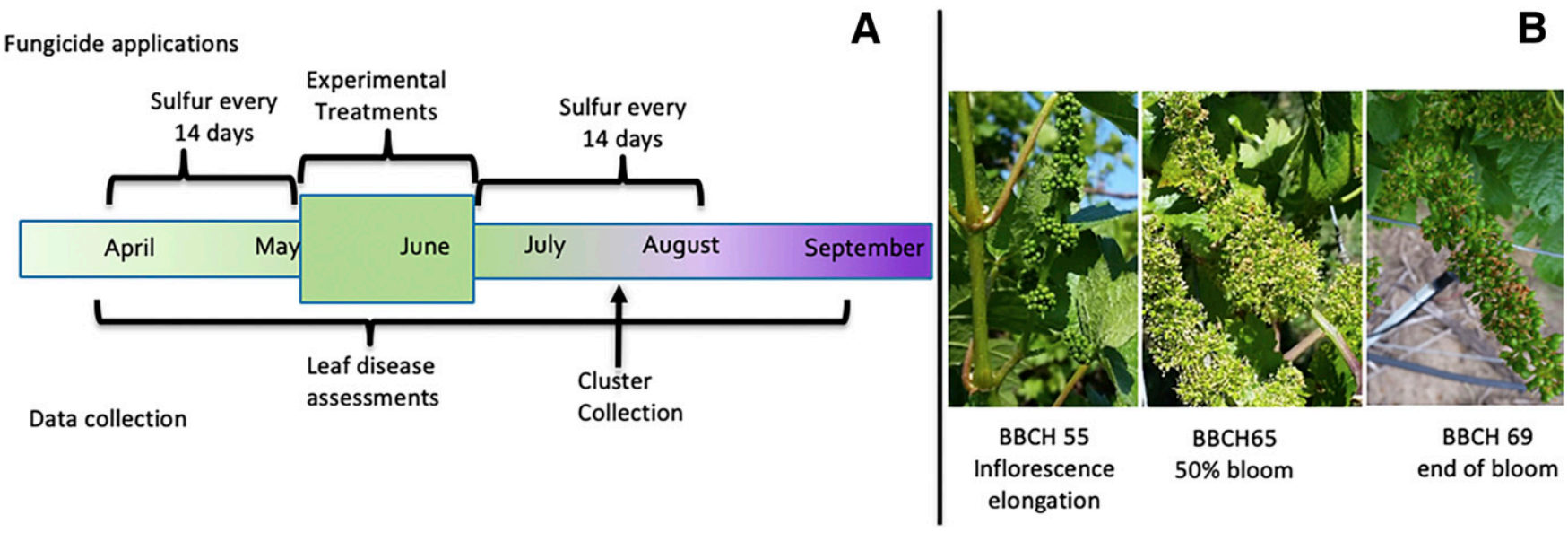

Fig. 2. Timing and crop phenology of treatments and data collection. A, Timeline of approximate fungicide application (upper) windows and the general timing of data collections (lower). Sulfur applications were made every 14 days prior to bud break until being suspended approximately 2 weeks prior to the estimated occurrence of each phenological stage to which redistributing fungicide was applied. Fourteen days after two sequential redistributing fungicide applications, the sulfur applications were resumed every 14 days until veraison. $\mathbf{B}$, Images of the growth stages at which treatments were initiated. 
fluopyram and quinoxyfen (two applications). The phenological treatments were initiated when $\geq 50 \%$ of the vineyard reached end of bloom for a total of four different fungicide treatments. Sulfur was resumed 14 days after the synthetic applications and continued until véraison.

Leaf disease incidence was monitored (as above) on the second and fourth vines within the three middle plots of each row (six vines per row) and the middle three vines of each water-treated control plot. Just prior to véraison, one cluster was collected from each monitored vine (six per experimental unit) into individual bags and frozen until assessed microscopically as described above.

Leaf disease incidence data were used to calculate absolute AUDPCs as described above. GLMM fitting and treatment contrasts were conducted as described above. A simple effects model containing all treatments was used to compare disease levels among the treatments.

\section{Results}

Detached leaf fungicide redistribution. Flutriafol and fluopyram had significantly larger areas of GPM inhibition (AOI) than the water control $(P<0.0001)$ (Table 2$)$ in the xylem redistribution assay, and they had 2.1 and 4.7 times larger AOI, respectively, than the next highest treatment, which resulted in a large portion of the lobe of the leaf free of mildew growth (not pictured). All other fungicides applied to the adaxial surface had an AOI that was not significantly different from the control $(P>0.05)$. Flutriafol, fluopyram, tebuconazole, and quinoxyfen had significantly larger translaminar AOIs than the control $(P<0.05)$, but flutriafol and fluopyram had 2.3 and 2.6 times higher AOIs, respectively, than tebuconazole, the next highest AOI treatment (Table 2). The AOIs of flutriafol and fluopyram indicated that those fungicides redistributed with translaminar activity in combination with xylem mobility. Quinoxyfen and tebuconazole had significantly larger translaminar AOI than the control $(P=0.03$ and 0.005 , respectively), but their AOIs were smaller than flutriafol or fluopyram. These results indicated that they could translocate through the leaf but had little additional xylem mobility. Metrafenone and trifloxystrobin inhibition of E. necator growth via the translaminar pathway was not significantly different from the control ( $P=0.2$ and 0.1 , respectively) (Table 2$)$. All fungicides tested had significantly larger vapor AOI than the control, except WS and quinoxyfen (Table 2$)(\mathrm{P}<0.05)$. Flutriafol had the highest vapor AOI at $1.47 \mathrm{~cm}^{2}$, showing a clear torus around the PTFE disc (not pictured); this was a 2.7-times-larger AOI than tebuconazole and metrafenone, both of which were still significantly different from the control ( $P=0.01$ and 0.01 , respectively) (Table 2$)$.

Fungicide translocation through calyptras. Fluopyram, trifloxystrobin, and tebuconazole resulted in proportions of infected berries of $0.060,0.011$, and 0.0082 , respectively, significantly lower than the water control $(0.35 ; P<0.05)$ (Fig. 3). The proportions of infected berries from WS and quinoxyfen treatments were not significantly different from the water control $(P>0.05)$.

Phenologically timed application experiment. Fluopyram treatments had lower mean AUDPC values as application time progressed, with the end of bloom application resulting in the lowest values in both years (Table 3). The end of bloom trifloxystrobin treatment resulted in significantly lower AUDPC values than the calendar sulfur in both years $(P \leq 0.05)$. When quinoxyfen was applied in 2016, lower AUDPC values occurred at the two later application timings. Overall, AUDPC values for all phenologically timed fungicide treatments were similar to or lower than that of the calendar sulfur control, and all were significantly lower than that of the nontreated control $(P<0.01)$.

Probabilities of berry infection varied among treatments both within and between fungicides (Table 3). Fluopyram and trifloxystrobin end of bloom applications resulted in significantly lower mean proportions of infected berries compared with calendar application of sulfur in both years $(P<0.05)$. End of bloom applications were the most effective application timing for quinoxyfen in both years, but they only resulted in significantly lower mean proportions of infected berries compared with the calendar sulfur control in 2016
$(P<0.0001)$. All application timings of tebuconazole and WS resulted in relatively high mean proportions of infected berries (from 0.33 to 0.78 ) that were not significantly different than the calendar sulfur control in both 2015 and 2016 (0.41 and 0.73, respectively; $P>0.05$ ) (Table 3). In the factorial analyses in 2015 and 2016, the mean proportion of infected berries was significantly influenced by the interaction between fungicide and application timing (drop in deviance test, $\chi^{2}=24.3$ and 29.0, respectively; df $=8$; one-sided $P<$ 0.01). In both 2015 and 2016 for fluopyram, quinoxyfen, and trifloxystrobin, odds ratios indicated that, at inflorescence elongation, berries had significantly higher odds of infection on average than when applied at end of bloom $(P<0.01)$ (Table 4). For inflorescence elongation and 50\% bloom comparisons, in both 2015 and 2016, fluopyram, quinoxyfen, and trifloxystrobin odds ratios indicated that, at inflorescence elongation, berries had significantly higher odds of infection than when applied at $50 \%$ bloom on average $(P<0.01)$ (Table 4), except for the case of trifloxystrobin in $2015(P=0.20)$. Mean odds ratios were close to one for all comparisons in WS and tebuconazole groups, indicating that application timing had no significant effect on the mean odds of berry infection in these treatments (Table 4).

Field redistribution assessment. All 50\% bloom and berry set applications of fluopyram, quinoxyfen, and trifloxystrobin had significantly lower disease levels on clusters covered with plastic bags compared with the nontreated control in both 2015 and 2016 (Table 3). Treatments in 2015 had variable probabilities across fungicides, with all phenological treatments having statistically similar $(P>0.05)$ mean probabilities of infection to the calendar sulfur control (Table 3). Fluopyram, quinoxyfen, and trifloxystrobin $50 \%$ bloom and end of bloom application timings resulted in the lowest mean probabilities of berry infection in both years (Table 3 ).

Fungicide rotation experiment. All fungicide treatments resulted in significantly less leaf and fruit disease compared with the nontreated control $(P<0.05)$ (Table 5). The fluopyram-quinoxyfen rotations resulted in significantly lower disease levels than other treatments in mean AUDPC values and berry incidence $(P<0.05)$.

\section{Discussion}

The results from this study indicate that timing applications of redistributing fungicides from late flowering to early berry development (50\% bloom and end of bloom) significantly improves GPM management on grape berries. Targeting redistributing fungicide applications to periods when they will most efficiently reduce disease,

Table 2. Mean areas of adaxial Erysiphe necator growth inhibition $\left(\mathrm{mm}^{2}\right)$ from fungicide redistribution assays on detached cultivar Pinot noir leaves where fungicide treatments were applied to the first major vein intersection on the outer lobes of the leaf

\begin{tabular}{lccr}
\hline & \multicolumn{3}{c}{ Detached leaf assays $^{\mathbf{v}}$} \\
\cline { 2 - 4 } Fungicide $^{\mathbf{u}}$ & Xylem $^{\mathbf{w}}$ & Translaminarw $^{\mathbf{w}}$ & Vapor $^{\mathbf{x}}$ \\
\hline Flutriafol & $578^{\mathrm{y}}$ & $290^{\mathrm{y}}$ & $147^{\mathrm{y}}$ \\
Fluopyram & $256^{\mathrm{y}}$ & $270^{\mathrm{y}}$ & $70^{\mathrm{y}}$ \\
Tebuconazole & 124 & $116^{\mathrm{y}}$ & $55^{\mathrm{z}}$ \\
Metrafenone & 107 & 74 & $54^{\mathrm{z}}$ \\
Wettable sulfur & 98 & 0 & 29 \\
Trifloxystrobin & 81 & 79 & $75^{\mathrm{y}}$ \\
Quinoxyfen & 56 & $99^{\mathrm{z}}$ & 25 \\
Water control & 12 & 0 & 0 \\
\hline
\end{tabular}

u Fungicide trade names and rates are listed in Table 1.

$\checkmark$ Mean values.

w Areas of inhibition on the adaxial leaf surface from abaxial fungicideimpregnated filter paper disc application.

$x$ Areas of inhibition surrounding the polytetrafluoroethylene fungicidetreated disc placed on the adaxial surface.

y Significant difference from the water control. $P<0.01$. $P$ values are adjusted for a group of seven tests.

z Significant difference from the water control. $P<0.05$. $P$ values are adjusted for a group of seven tests. 
such as late bloom and early berry development, may allow their overall use to be decreased. Reducing use of synthetic products while maintaining production of fruit with low disease levels has multifaceted benefits for the grower. Synthetic fungicides are significantly more expensive than sulfur or comparable products in cost of application (Sambucci et al. 2014). By reducing their use, economic and environmental costs associated with application could also be reduced.

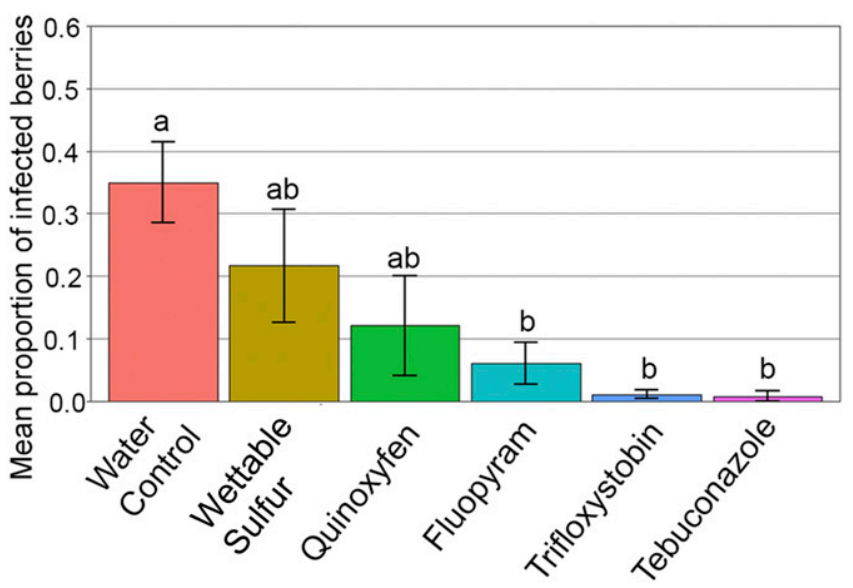

Fig. 3. Mean proportions of infected berries separated by fungicide in the fungicide through calyptra study, where applications were made before calyptra fall and infructescences were inoculated after calyptra fall. Treatments with similar letters do not differ significantly from each other at $P<0.05$ based on the Tukey honest significant difference test.
Many synthetic fungicides are prone to resistance development by phytopathogenic fungi, and reducing the number of repeated applications of high-risk fungicides may reduce selection pressures for fungicide resistance (Hobbelen et al. 2014; Jørgensen et al. 2017; Mikaberidze et al. 2017; van den Bosch et al. 2014). By focusing applications of synthetic fungicides in the window of peak berry susceptibility, their use can be minimized while still producing fruit with acceptably low disease levels. The strategy of focusing synthetic applications into the window of bloom and early berry development has been investigated before and determined to be a viable strategy to get efficacious GPM control on clusters, even in high-disease pressure situations (Gadoury et al. 2003; Kast and Bleyer 2011).

Bloom and early berry development are critical times to make effective fungicide applications targeted at GPM, because inflorescences are most susceptible to infection by E. necator from early bloom until 3 to 4 weeks postbloom (Gadoury et al. 2003; Moyer et al. 2018). The results of this study agree with a similar experiment conducted by Gadoury et al. (2003), where two sequential applications of kresoxim-methyl with a 10-day interval were made to individual shoots starting at grape bloom and provided as much control of GPM on grape berries as a full-season fungicide program of eight sprays. In this study, applications of fluopyram, quinoxyfen, and trifloxystrobin initiated at bloom resulted in low mean proportions of infected berries; however, applications initiated at the end of bloom were more effective. This could be because fungicides that adhered to the calyptra were lost when it detached from the inflorescence. However, this conclusion would be contrary to the data from the greenhouse redistribution study showing that applications of fungicides to the calyptras in the greenhouse resulted in significantly lower berry infection (Fig. 3). The difference in these results may be because the greenhouse study limited the potential for berry infection to a discrete point in time approximately 7 days postfungicide

Table 3. Grape leaf and berry disease incidence (area under disease progress curve [AUDPC] and proportions of infected berries, respectively) from 2015 and 2016 small plot phenological application timing experiments conducted on cultivar Pinot noir vines

\begin{tabular}{|c|c|c|c|c|c|c|}
\hline $\begin{array}{l}\text { Fungicide and application } \\
\text { timing }(\mathrm{BBCH})^{\mathrm{v}}\end{array}$ & $\begin{array}{c}2015 \\
\text { AUDPC }\end{array}$ & $\begin{array}{c}2016 \\
\text { AUDPC }\end{array}$ & $\begin{array}{l}2015 \text { Unbagged disease } \\
\text { proportions }^{w}\end{array}$ & $\begin{array}{l}2016 \text { Unbagged disease } \\
\text { proportions }^{w}\end{array}$ & $\begin{array}{l}2015 \text { Bagged disease } \\
\text { proportions }^{w}\end{array}$ & $\begin{array}{l}2016 \text { Bagged disease } \\
\text { proportions }^{w}\end{array}$ \\
\hline \multicolumn{7}{|l|}{ Calendar sulfur } \\
\hline Calendar & $105 \pm 16$ & $156 \pm 4$ & $0.41(0.24-0.61)$ & $0.73(0.61-0.82)$ & $-{ }^{x}$ & - \\
\hline \multicolumn{7}{|l|}{ No treatment } \\
\hline Calendar & $253 \pm 19^{y}$ & $403 \pm 46^{y}$ & $0.73(0.55-0.86)$ & $0.88(0.81-0.93)$ & - & - \\
\hline \multicolumn{7}{|l|}{ Fluopyram } \\
\hline 55 & $92 \pm 17$ & $103 \pm 6^{z}$ & $0.35(0.20-0.55)$ & $0.18(0.11-0.28)^{\mathrm{y}}$ & $0.45(0.30-0.60)$ & $0.27(0.18-0.37)$ \\
\hline 65 & $60 \pm 12^{z}$ & $60 \pm 8^{y}$ & $0.036(0.016-0.081)^{\mathrm{y}}$ & $0.038(0.021-0.069)^{\mathrm{y}}$ & $0.21(0.13-0.33)$ & $0.16(0.10-0.23)$ \\
\hline 69 & $38 \pm 13^{y}$ & $50 \pm 8^{y}$ & $0.045(0.020-0.10)^{\mathrm{y}}$ & $0.020(0.010-0.039)^{\mathrm{y}}$ & $0.29(0.18-0.43)$ & $0.17(0.11-0.26)$ \\
\hline \multicolumn{7}{|l|}{ Quinoxyfen } \\
\hline 55 & $106 \pm 14$ & $141 \pm 31$ & $0.56(0.36-0.74)$ & $0.45(0.33-0.59)^{\mathrm{z}}$ & $0.64(0.49-0.76)$ & $0.38(0.27-0.50)$ \\
\hline 65 & $76 \pm 12$ & $71 \pm 8^{y}$ & $0.21(0.11-0.37)$ & $0.098(0.058-0.16)^{\mathrm{y}}$ & $0.25(0.16-0.39)$ & $0.18(0.11-0.26)$ \\
\hline 69 & $92 \pm 16$ & $58 \pm 5^{\mathrm{y}}$ & $0.13(0.066-0.26)$ & $0.097(0.057-0.16)^{\mathrm{y}}$ & $0.34(0.22-0.48)$ & $0.14(0.087-0.21)$ \\
\hline \multicolumn{7}{|l|}{ Wettable sulfur } \\
\hline 55 & $77 \pm 17$ & $138 \pm 21$ & $0.50(0.31-0.69)$ & $0.79(0.68-0.86)$ & $0.50(0.35-0.64)$ & $0.70(0.59-0.79)$ \\
\hline 65 & $87 \pm 16$ & $111 \pm 20^{\mathrm{z}}$ & $0.59(0.40-0.76)$ & $0.50(0.36-0.63)$ & $0.52(0.37-0.66)$ & $0.56(0.44-0.68)$ \\
\hline 69 & $99 \pm 5$ & $117 \pm 26$ & $0.58(0.38-0.75)$ & $0.70(0.57-0.80)$ & $0.70(0.56-0.81)$ & $0.57(0.45-0.68)$ \\
\hline \multicolumn{7}{|l|}{ Tebuconazole } \\
\hline 55 & $74 \pm 13$ & $119 \pm 17$ & $0.52(0.33-0.70)$ & $0.63(0.50-0.75)$ & $0.35(0.23-0.49)$ & $0.60(0.48-0.71)$ \\
\hline 65 & $101 \pm 18$ & $75 \pm 7^{y}$ & $0.62(0.42-0.78)$ & $0.63(0.50-0.75)$ & $0.69(0.55-0.80)$ & $0.67(0.55-0.77)$ \\
\hline 69 & $97 \pm 7$ & $85 \pm 23^{y}$ & $0.33(0.18-0.53)$ & $0.69(0.56-0.79)$ & $0.51(0.36-0.65)$ & $0.65(0.53-0.75)$ \\
\hline \multicolumn{7}{|l|}{ Trifloxystrobin } \\
\hline 55 & $76 \pm 12$ & $84 \pm 16^{y}$ & $0.28(0.15-0.47)$ & $0.36(0.25-0.49)^{\mathrm{y}}$ & $0.30(0.19-0.44)$ & $0.31(0.22-0.43)$ \\
\hline 65 & $77 \pm 7$ & $91 \pm 7 y$ & $0.14(0.066-0.26)$ & $0.13(0.078-0.21)^{\mathrm{y}}$ & $0.24(0.15-0.37)$ & $0.36(0.26-0.48)$ \\
\hline 69 & $67 \pm 13^{z}$ & $74 \pm 16^{y}$ & $0.073(0.033-0.15)^{\mathrm{y}}$ & $0.11(0.064-0.17)^{\mathrm{y}}$ & $0.25(0.16-0.38)$ & $0.20(0.13-0.29)$ \\
\hline
\end{tabular}

$\checkmark \mathrm{BBCH}$ refers to inflorescence elongation. BBCH 65 refers to full bloom, and BBCH 69 refers to end of bloom.

${ }^{w}$ Proportions are followed by asymptotic $95 \%$ confidence intervals in parentheses. Bagged clusters were covered with zip top plastic bags during each phenologically timed application so that they were not directly treated during those applications. Bags were removed immediately following the application. Unbagged clusters were not covered, and they were directly treated with each fungicide application.

$x$ No data.

y Significant difference from the calendar sulfur treatment using linear contrasts of means with $P$ value adjusted for a group of 16 tests for AUDPC data and least squared means for berry infection proportion data adjusted using the Dunnett method. $P<0.01$.

z Significant difference from the calendar sulfur treatment using linear contrasts of means with $P$ value adjusted for a group of 16 tests for AUDPC data and least squared means for berry infection proportion data adjusted using the Dunnett method. $P<0.05$. 
application, whereas in field studies, the conditions for new infections were met daily for several weeks. Additionally, the lower disease levels on berries at the end of bloom treatments could also be related to fungicide absorption through the berry cuticle.

At the end of bloom, berries are anatomically predisposed to efficiently receive and absorb active ingredient based on the large cuticular surface area and lack of cuticular waxes. The grape berry cuticle starts to be formed 1 week prior to anthesis, and by full bloom, cuticular ridges are present and tightly appressed (Casado and Heredia 2001). At fruit set, the grape berry cuticle is characterized by numerous ridges that are spread apart, increasing the cuticular surface area (Casado and Heredia 2001; Rosenquist and Morrison 1988), which could increase the amount of fungicide absorbed. At fruit set, there is also a low amount of epicuticular wax accumulated on berries (Rosenquist and Morrison 1988). Epicuticular wax increases the hydrophobicity of grape berries, making it more difficult for fungicide suspensions to adhere and active ingredient to subsequently be absorbed. At 6 days postbloom, rudimentary wax crystals start to form; by 18 days postbloom, cuticular ridges are still present, but wax platelets have started to cover the grape berry (KyoungHee et al. 2010). An application at 10- to 14-days postbloom, such as in this study, should allow for fungicide to contact the berry cuticle before berries are completely covered with epicuticular wax. In addition, when applications were made 10- to 14-days postbloom, berries were physically larger, allowing for more fungicidal spray interception. Thus, in relation to grape flowering, fungicide deposition and absorption would likely be maximized at end of bloom (Rosenquist and Morrison 1988).

Clusters are difficult to adequately cover with fungicide applications owing to their location within the canopy (Austin et al. 2011; Wise et al. 2010). The absorption of fluopyram, trifloxystrobin, and quinoxyfen into grape berries and subsequent redistribution may have enhanced coverage of clusters to effectively protect a higher proportion of berries from E. necator infection than sulfur or tebuconazole. Fluopyram, trifloxystrobin, and quinoxyfen are capable of translocating through leaves, and all but quinoxyfen were demonstrated to translocate through calyptras (Fig. 3 and Table 2). Although quinoxyfen did not exhibit as much redistribution as fluopyram or trifloxystrobin, this could be because of the moderated greenhouse and growth chamber conditions in the redistribution experiments, which were not representative of the variable conditions possible in a field scenario, such as higher temperatures and lower RH. In addition, although tebuconazole redistributed through calyptras and protected clusters, its mode of action and physical properties could have played a role in its lack of efficacy in a field scenario. Tebuconazole (FRAC 3) applied at bloom did not as effectively control the microscopic GPM incidence on grape berries (Table 3) compared with other treatments. Dimethylation inhibitor (DMI) fungicides exhibit fungistatic effects on established $E$. necator colonies, halting their growth (Gadoury et al. 2007). The treatments containing two consecutive applications of tebuconazole did not suppress disease as effectively as other treatments, which may be due to inadequate residual activity of the fungicide needed to prevent formation of diffuse colonies on berries (Gadoury et al. 2003, 2007; Jyot et al. 2010) of colonies preexisting applications. In addition, some of the lower efficacy of tebuconazole on grape berries could be because of increase tolerance to DMI fungicides in E. necator populations (Erickson and Wilcox 1997) (W. F. Mahaffee, unpublished data). DMI-tolerant E. necator isolates have been found throughout the western United States (W. F. Mahaffee, personal observation). Conversely, the higher efficacy of fluopyram, quinoxyfen, and trifloxystrobin on berries could be owing to their mode of action that is effective at stopping spores in the initial stages of host tissue colonization (Bartlett et al. 2002; Glattli et al. 2011; Wheeler et al. 2003). By inhibiting the initial stages of infection, they may be more effective at preventing formation of diffuse E. necator colonies on berries.

The majority of infections observed over the course of this study were diffuse colonies that are not commonly observed by the macroscopic or densimetric grape-sorting processes used by viticulturists to evaluate grape quality and coordinate harvest. However, these diffuse colonies have been associated with increased levels of insect infestation, higher levels of spoilage microorganisms, and bunch rot (Gadoury et al. 2007). Previous studies have determined that a low proportion of diseased berries can result in off flavors in the resulting wine, but mildew levels in these studies were assessed macroscopically (Ough and Berg 1979; Stummer et al. 2003). Thus, reduction in fruit infection observed using a mobile fungicide may also have other benefits to grape and wine quality. Further determination of the link between diffuse powdery mildew colonies and fruit quality at harvest could improve fruit quality estimation and potential for late-season bunch spoilage owing to bunch rot or other secondary spoilage diseases.

This study and others suggest that making fungicide applications to manage powdery mildew on wine grape clusters should be focused in the critical window of bloom to 2- to 4-weeks postflowering, when berries gain ontogenic resistance (Gadoury et al. 2003; Moyer et al.

Table 4. Odds of berry infection ratios comparing within fungicide application timings with one another from 2015 and 2016 small plot phenological application timing experiments conducted on cultivar Pinot noir vines

\begin{tabular}{lcc}
\hline $\begin{array}{l}\text { Fungicide and contrast } \\
\text { (BBCH) }^{\mathbf{y}}\end{array}$ & 2015 Odds ratios & \\
\hline Fluopyram & 2016 Odds ratios \\
$\quad 55 / 65$ & $14.51(3.98-52.82)$ & $5.55(2.14-14.41)$ \\
$55 / 69$ & $11.53(3.15-42.21)$ & $10.64(3.83-29.60)$ \\
$65 / 69$ & $0.79(0.21-3.05)$ & $1.92(0.65-5.61)$ \\
Quinoxyfen & & \\
$55 / 65$ & $4.71(1.35-16.37)$ & $7.62(3.08-18.82)$ \\
$55 / 69$ & $7.96(2.28-27.75)$ & $7.65(3.08-18.97)$ \\
$65 / 69$ & $1.69(0.48-5.93)$ & $1.00(0.39-2.55)$ \\
Wettable sulfur & & \\
$55 / 65$ & $0.67(0.19-2.34)$ & $3.72(1.53-9.02)$ \\
$55 / 69$ & $0.71(0.20-2.47)$ & $1.60(0.66-3.89)$ \\
$65 / 69$ & $1.06(0.31-3.66)$ & $0.43(0.18-1.04)$ \\
Tebuconazole & & \\
$55 / 65$ & $0.66(0.19-2.29)$ & $1.01(0.42-2.44)$ \\
$55 / 69$ & $2.15(0.62-7.45)$ & $0.78(0.32-1.89)$ \\
$65 / 69$ & $3.26(0.94-11.33)$ & $0.77(0.32-1.86)$ \\
Trifloxystrobin & & \\
$55 / 65$ & $2.50(0.72-8.75)$ & $3.77(1.54-9.24)$ \\
$55 / 69$ & $4.98(1.40-17.74)$ & $4.69(1.91-11.52)$ \\
$65 / 69$ & $1.99(0.55-7.15)$ & $1.24(0.50-3.10)$ \\
\hline
\end{tabular}

${ }^{\mathrm{y}} \mathrm{BBCH} 55, \mathrm{BBCH} 65$, and $\mathrm{BBCH} 69$ are inflorescence elongation, 50\% bloom, and end of bloom, respectively.

${ }^{\mathrm{z}}$ Ratios are followed by asymptotic $95 \%$ confidence intervals in parentheses, where one included in the confidence interval indicates no significant difference in odds of berry infection $(P<0.05)$ between the two timings.

Table 5. Leaf incidence (area under disease progress curves [AUDPCs]) and mean proportions of infected berries from the 2017 fungicide rotation experiment on rows of cultivar Pinot noir vines

\begin{tabular}{lcc}
\hline Treatment $^{\mathbf{w}}$ & Mean AUDPC $^{\mathbf{x}}$ & $\begin{array}{c}\text { Mean proportion of } \\
\text { infected berries }^{\mathbf{y}}\end{array}$ \\
\hline Nontreated & $558 \pm 17 \mathrm{~A}$ & $1.00(0.99-1.00)^{\mathrm{z}}$ \\
Calendar sulfur & $226 \pm 23 \mathrm{~B}$ & $0.85(0.72-0.93)$ \\
Quinoxyfen & $177 \pm 21 \mathrm{~B}$ & $0.57(0.38-0.75)^{\mathrm{z}}$ \\
Fluopyram & $163 \pm 28 \mathrm{~B}$ & $0.35(0.19-0.54)^{\mathrm{z}}$ \\
Fluopyram-quinoxyfen & $90 \pm 5 \mathrm{C}$ & $0.076(0.035-0.16)^{\mathrm{z}}$ \\
Quinoxyfen-fluopyram & $83 \pm 3 \mathrm{C}$ & $0.059(0.026-0.13)^{\mathrm{z}}$ \\
\hline
\end{tabular}

${ }^{w}$ Applications of these products were initiated at end of bloom (BBCH 69) after the vines had been receiving 14-day sulfur applications since shoots were 20 - to $30-\mathrm{cm}$ long. Sulfur was resumed after the listed application(s).

${ }^{x}$ Means followed by different letters are significantly different from one another at $P<0.05$ using the Tukey honest significant difference test.

y Proportions are followed by asymptotic $95 \%$ confidence intervals.

z Significant difference from the calendar sulfur treatment $(P<0.01)$ using linear contrasts of means with $P$ value adjusted for a group of five tests. 
2018). In addition to wine grapes, timing application of redistributing fungicides to specific phenological growth stages could be an important aspect to improving disease management and chemical use efficiency in other small fruit production systems. In this study, fungicide redistribution via vapor and apoplastic pathways likely played a role in the higher efficacy of applications timed to grape flowering stages. Concentrating applications in the window of bloom until 2- to 4-weeks postbloom may provide an effective strategy for wine grape growers in western Oregon seeking to produce fruit with low disease levels and minimum synthetic chemical inputs. Reduced synthetic inputs may also have the added benefit of a reduction in selection pressure for fungicide-resistant E. necator strains.

\section{Acknowledgments}

We thank Tara Neill, Andy Albrecht, Chris Gorman, Carly Allen, and Bailey Williams for technical support. We also thank the reviewers for their helpful suggestions to improve the manuscript. The use of trade, firm, or corporation names in this publication is for the information and convenience of the reader. Such use does not constitute an official endorsement or approval by the U.S. Department of Agriculture or the Agricultural Research Service of any product or service to the exclusion of others that may be suitable.

\section{Literature Cited}

Austin, C. N., Grove, G. G., Meyers, J. M., and Wilcox, W. F. 2011. Powdery mildew severity as a function of canopy density: Associated impacts on sunlight penetration and spray coverage. Am. J. Enol. Vitic. 62:23-31.

Bartlett, D., Clough, J., Godwin, J., Hall, A., Hamer, M., and Parr-Dobrzanski, B. 2002. The strobilurin fungicides. Pest Manag. Sci. 58:649-662.

Bettiga, L. J., Gubler, W. D., and Leavitt, G. M. 2013. Powdery mildew. Pages 137-149 in: Grape Pest Management. L. J. Bettiga, ed. University of California, Richmond, CA.

Bolker, B. M., Brooks, M. E., Clark, C. J., Geange, S. W., Poulsen, J. R., Stevens, M. H. H., and White, J.-S. S. 2009. Generalized linear mixed models: A practical guide for ecology and evolution. Trends Ecol. Evol. 24:127-135.

Casado, C. G., and Heredia, A. 2001. Ultrastructure of the cuticle during growth of the grape berry (Vitis vinifera L.). Physiol. Plant. 111:220-224.

Cousins, P. 2012. Small but mighty: 'Pixie' grapevine speeds up the pace of grape genetics research and breeding. Appellation Cornell Newsl. 10:1-4.

Erickson, E. O., and Wilcox, W. F. 1997. Distributions of sensitivities to three sterol demethylation inhibitor fungicides among populations of Uncinula necator sensitive and resistant to triadimefon. Phytopathology 87:784-791.

Ficke, A., Gadoury, D. M., and Seem, R. C. 2002. Ontogenic resistance and plant disease management: A case study of grape powdery mildew. Phytopathology 92:671-675.

Gadoury, D. M., Cadle-Davidson, L., Wilcox, W. F., Dry, I. B., Seem, R. C., and Milgroom, M. G. 2012. Grapevine powdery mildew (Erysiphe necator): A fascinating system for the study of the biology, ecology and epidemiology of an obligate biotroph. Mol. Plant Pathol. 13:1-16.

Gadoury, D. M., Seem, R. C., Ficke, A., and Wilcox, W. F. 2003. Ontogenic resistance to powdery mildew in grape berries. Phytopathology 93:547-555.

Gadoury, D. M., Seem, R. C., Wilcox, W. F., Henick-Kling, T., Conterno, L., Day, A., and Ficke, A. 2007. Effects of diffuse colonization of grape berries by Uncinula necator on bunch rots, berry microflora, and juice and wine quality. Phytopathology 97:1356-1365.

Gee, C. T., Gadoury, D. M., and Cadle-Davidson, L. 2008. Ontogenic resistance to Uncinula necator varies by genotype and tissue type in a diverse collection of Vitis spp. Plant Dis. 92:1067-1073.

Gent, D. H., Grove, G. G., Nelson, M. E., Wolfenbarger, S. N., and Woods, J. L. 2014. Crop damage caused by powdery mildew on hop and its relationship to late season management. Plant Pathol. 63:625-639.

Gianessi, L. P., and Reigner, N. 2005. The Value of Fungicides in U.S. Crop Production. Croplife Foundation, Washington, DC.

Glattli, A., Grote, T., and Stammler, G. 2011. SDH-inhibitors: History, biological performance and molecular mode of action. Pages 159-170 in: Modern Fungicides and Antifungal Compounds VI. H. W. Dehne, H. B. Deising, U. Gisi, K. H. Kuck, P. E. Russell, and H. Lyr, eds. Deutsche Phytomedizinische Gesellschaft (German Phytomedicine Society), Brunswick, Germany.

Harrison, X. A. 2014. Using observation-level random effects to model overdispersion in count data in ecology and evolution. PeerJ 2:e616.

Hartig, F. 2016. DHARMa: Residual Diagnostics for Hierarchical (Multi-Level/ Mixed) Regression Models. https://cran.r-project.org/package=DHARMa

Hellman, E. W. 2003. Oregon Viticulture. Oregon State University Press, Corvallis, OR

Henry, M. J. 2003. Fungicides, quinoxyfen. Pages $872-873$ in: The Encyclopedia of Agrochemicals. J. R. Plimmer, D. W. Gammon, and N. A. Ragsdale, eds. John Wiley \& Sons, Hoboken, NJ.

Hobbelen, P. H. F., Paveley, N. D., and van den Bosch, F. 2014. The emergence of resistance to fungicides. PLoS One 9:e91910.
Hoffman, L. E., Wilcox, W. F., Gadoury, D. M., Seem, R. C., and Riegel, D. G. 2004. Integrated control of grape black rot: Influence of host phenology, inoculum availability, sanitation, and spray timing. Phytopathology 94 641-650.

Jørgensen, L. N., van den Bosch, F., Oliver, R. P., Heick, T. M., and Paveley, N. D 2017. Targeting fungicide inputs according to need. Annu. Rev. Phytopathol. 55:181-203.

Jyot, G., Arora, P. K., Sahoo, S. K., Singh, B., and Battu, R. S. 2010. Persistence of trifloxystrobin and tebuconazole on grape leaves, grape berries and soil. Bull. Environ. Contam. Toxicol. 84:305-310.

Kast, W. K., and Bleyer, K. 2011. Efficacy of sprays applied against powdery mildew (Erysiphe necator) during a critical period for infections of clusters of grapevines (Vitis vinifera). J. Plant Pathol. 93:S29-S32.

Klittich, C. J. 2014. Fungicide mobility and the influence of physical properties. Pages 95-109 in: Retention, Uptake, and Translocation of Agrochemicals in Plants. K. Myung, N. M. Satchivi, and C. K. Kingston, eds. American Chemical Society, Washington, DC.

KyoungHee, S., InMyung, C., KyuHwan, C., JaeMan, L., and HeeSeung, P. 2010 Morphological development and chemical composition of epicuticular wax crystals in "Campbell Early" grape. Hortic. Environ. Biotechnol. 51:253-256.

Lenth, R.V., 2018. emmeans: Estimated Marginal Means, aka Least-Squares Means. R Package version, 1.3.0. https://cran.r-project.org/package=emmeans

Lorenz, D. H., Eichhorn, K. W., Bleiholder, H., Klose, R., Meier, U., and Weber, E. 1995. Growth stages of the grapevine: Phenological growth stages of the grapevine (Vitis vinifera L. ssp. vinifera) —Ccdes and descriptions according to the extended BBCH scale. Aust. J. Grape Wine Res. 1:100-103.

Lybbert, T. J., Magnan, N., and Gubler, W. D. 2016. Multidimensional responses to disease information: How do winegrape growers react to powdery mildew forecasts and to what environmental effect? Am. J. Agric. Econ. 98:383-405.

Madden, L. V., Hughes, G., and van den Bosch, F. 2007. Measuring plant diseases. Pages 11-31 in: The Study of Plant Disease Epidemics. L. V. Madden, G. Hughes, and F. van den Bosch, eds. American Phytopathological Society, St. Paul, MN.

Mendiburu, F. 2016. agricolae: Statistical Procedures for Agricultural Research https://cran.r-project.org/package=agricolae

Mikaberidze, A., Paveley, N., Bonhoeffer, S., and van den Bosch, F. 2017 Emergence of resistance to fungicides: The role of fungicide dose. Phytopathology 107:545-560.

Moyer, M. M., Newhouse, J. M., and Grove, G. G. 2018. Adjusting product timing during the powdery mildew "critical window" to improve disease management. Catal. Discov. Pract. 2:7-14.

Nelson, M. E., Gent, D. H., and Grove, G. G. 2015. Meta-analysis reveals a critical period for management of powdery mildew on hop cones. Plant Dis. 99: 632-640.

Ough, C., and Berg, H. 1979. Powdery mildew sensory effect on wine. Am. J. Enol. Vitic. 30:321.

Pinheiro, J., Bates, D., DebRoy, S., Sarkar, D., and R Core Team. 2016. nlme: Linear and Nonlinear Mixed Effects Models. R Package version, 1.2.1. http:// cran.r-project.org/package $=$ nlme

Quinn, J. A., and Powell, C. C. 1982. Effects of temperature, light, and relative humidity on powdery mildew of Begonia. Phytopathology 72:480-484.

R Core Team. 2016. R: A Language and Environment for Statistical Computing. R Foundation for Statistical Computing, Vienna, Austria.

Rosenquist, J. K., and Morrison, J. C. 1988. The development of the cuticle and epicuticular wax of the grape berry. Vitis 27:63-70.

Sambucci, O., Alston, J., and Fuller, K. 2014. The costs of powdery mildew management in grapes and the value of resistant varieties: Evidence from California. Working paper 1402, RMI-CWE, University of California, Davis, CA.

Sambucci, O., Lawell, C.-Y. L., and Lybbert, T. J. 2017. The spraying decisions of grape growers in response to disease forecasting information: A dynamic structural econometric model. Working paper, University of California, Davis, CA.

Shavrukov, Y. N., Dry, I. B., and Thomas, M. R. 2004. Inflorescence and bunch architecture development in Vitis vinifera L. Aust. J. Grape Wine Res. 10:116-124.

Stummer, B. E., Francis, I. L., Markides, A. J., and Scott, E. S. 2003. The effect of powdery mildew infection of grape berries on juice and wine composition and on sensory properties of Chardonnay wines. Aust. J. Grape Wine Res. 9:28-39.

van den Bosch, F., Oliver, R., van den Berg, F., and Paveley, N. 2014. Governing principles can guide fungicide-resistance management tactics. Annu. Rev. Phytopathol. 52:175-195.

Warneke, B., Yamagata, J., Neill, T., Miles, T., and Mahaffee, W. 2016. Detection of quinone outside inhibitor resistant isolates of Erysiphe necator in Oregon vineyards. Phytopathology S71.

Warnes, G., Bolker, B., Lumley, T., and Johnson, R. 2015. gmodels: Various R Programming Tools for Model Fitting. https://rdrr.io/cran/gmodels/

Wheeler, I. E., Hollomon, D. W., Gustafson, G., Mitchell, J. C., Longhurst, C., Zhang, Z., and Gurr, S. J. 2003. Quinoxyfen perturbs signal transduction in barley powdery mildew (Blumeria graminis f.sp. hordei). Mol. Plant Pathol. 4:177-186.

Wise, J. C., Jenkins, P. E., Schilder, A. M. C., Vandervoort, C., and Isaacs, R. 2010. Sprayer type and water volume influence pesticide deposition and control of insect pests and diseases in juice grapes. Crop Prot. 29: $378-385$ 